\title{
A STATIC NON-LINEAR CONTROLLED BRIDGE TYPE FAULT CURRENT LIMITER FOR TRANSIENT STABILITY AUGMENTATION OF MULTI-MACHINE POWER SYSTEM
}

\section{Vinothkumar A,}

PG Scholar [PSE], Dept. Of EEE Adhiyamaan College of Engineering , Housr, Tamilnadu, India

\section{Karthikeyan V,}

Assistant Professor, Dept. of EEE, Adhiyamaan College of Engineering, Hosur, Tamilnadu, India

\begin{abstract}
This paper implements Fault Current Limiting (FCL) requirements and proposed a calculation method to determine the required dc reactor value, for the purpose of the converter continuous operation during dc faults. On this basis, the Bridge-Type Fault Current Limiter (BFCL) using static non-linear controller was proposed for using in the dc grid, due to merits including minor negative influence on dc grid traditional operation, fast response to dc faults and efficient coordination with the DC Circuit Breaker (DCCB). The parameter style principle of the bridge-type FCL for dc grid was conjointly mentioned. Then the scaled-down dc experiment take a look at circuit was designed to verify the rule and performance of the bridge-type FCL. The simulation and experimental results are presented to clarify the theory and feasibility of the proposed FCL at different points of IEEE 30-bus power system, which manifest simple structure of the circuit and show feasibility of the proposed FCL.
\end{abstract}

Keywords: Fault Current Limiter (FCL); Bridge-Type Fault Current Limiter (BFCL); DC Circuit Breaker(DCCB); Distributed Generations(DGS); Renewable Energy(RE); Alternative Energy(AE); Storage Element (SE)

Cite this Article: Vinothkumar A and Karthikeyan V, A Static Non-Linear Controlled Bridge type Fault Current Limiter for Transient Stability Augmentation of MultiMachine Power System, International Journal of Electrical Engineering \& Technology, 10(1), 2019, pp.11-16 .

http://iaeme.com/Home/issue/IJEET?Volume=10\&Issue=1

\section{INTRODUCTION}

The Smart grid is being developed as the next generation power systems. These sensible grids comprehend interconnected microgrids, especially at the distribution level where Distributed 
Generations (DGs) are increasingly used. The DG technologies can be classified into power generation from Renewable Energy (RE) resources such as wind, photovoltaic, micro-hydro, biomass, geothermal, ocean wave and tides, the clean Alternative Energy (AE) generation technologies such as fuel cells and microturbines, as well as the traditional rotational machine based technologies such as diesel generators. Due to many edges of those several sources like cleanness and easy technologies, compounded with increasing demands for electrical energy and the exhaustible nature of fossil fuels, the RE and AE-based DGs play a vital role in microgrids.

The microgrids can work in grid-connected or stand-alone operation modes. Particularly the stand-alone operation, although may only for very limited period, can provide improved reliability to the smart grids. Some other systems, such as electric vehicles can be considered as always operating in stand-alone mode. Due to the intermittent nature of renewable energy resources, other energy sources (such as diesel) and Storage Elements (SEs) are critical part to enable the stand-alone operation of microgrids or to smooth the microgrid power during grid connected operation. SEs can be classified into two categories: capacity-oriented energy storage and access-oriented energy storage. Capacity-oriented energy storage does not have fast response time and they are used for long-term energy balancing to buffer out lowfrequency power oscillation of DGs output power and compensate intermittency of renewable energy sources in microgrids. Batteries, pumped hydroelectric systems, Compressed Air Energy Storage (CAES), and hydrogen storage are types of capacity-oriented energy storage. Access-oriented storage devices have a fast response time and they are responsible for short time disturbances in microgrids, by providing the high-frequency component of power. They can supply or absorb the high-power transients with high power density Flywheels, supercapacitors, and Superconducting Magnetic Energy Storage (SMES) are considered as access-oriented storage devices. The bridge type fault current limiter (BFCL) is currently a very much popular auxiliary balanced and unbalanced permanent as well as stability improving device to the power engineers and researchers throughout the world. Day by day, it is getting more attraction for its simple structure, low cost and feasible implementation characteristics. But, up to now, there is no detailed analysis of its proper and rigid control structure. Although there is an interesting work on the control structure of bridge type fault current limiter but the proposed control system lacks in viable implementation of generator responses as any control status. Moreover, it depends only on the grid current and voltage responses which can change nonlinearly any time. The line current variation during a fault is compared with a predefined threshold line current value, which can vary depending upon the systems nature and fault condition.

Therefore, as the power system is nonlinear in nature, a nonlinear controller for the bridge type fault current limiter will be reasonable from the view point of stability improvement of the power systems. As Static non-linear controller is a nonlinear controller with simplicity, it can be easily implemented for power system stability improvement. It is a very simple nonlinear controller based on simple "IF-THEN" logic. It resembles human deciding with its ability to figure from approximate information and realize precise solutions.

This paper proposes the static non -linear controlled bridge type FCL to improve the transient stability of multi-machine power systems. To the best of our knowledge, there is no application of any nonlinear controller for the bridge type FCL. So far, the bridge type FCL has been applied to stability improvement in wind generator system and single machine power system. But, there is no report available on the bridge type FCL application to the transient stability improvement of multi-machine power system.

For demonstrating the effectiveness of the proposed Static non-linear controlled bridge type FCL in transient stability enhancement, the IEEE 30-bus power system model has been 
used. Both temporary faults are considered. Simulations are performed by using the MATLAB/SIMULINK software. Moreover, instead of conventional reclosing, we considered the total kinetic energy based optimal reclosing of circuit breakers along with the static nonlinear controlled bridge type FCL for improving the transient stability of the multi-machine power systems.

\section{EXISTINGSYSTEM}

The bridge-type fault current limiter (FCL) was proposed for using in the dc grid, due to merits including minor negative influence on dc grid normal operation, fast response to dc faults and efficient coordination with the dc circuit breaker (DCCB). In Existing system to apply the bridge-type FCL in the dc gird for replacing the dc reactor directly installed on the dc line. As we know, the bridge type FCL was first invented for the ac system. When used in the MMC-based dc gird, it has a different working principle with the parameters redesigned.

\section{PROPOSED SYSTEM}

In this paper, in order to evaluate the performance of the existing coordinated operation of the fuzzy logic controlled bridge type fault current limiter and optimal reclosing in more detail, an alternative static nonlinear controller is proposed in this paper. The static nonlinear controller can be represented by a simple equation

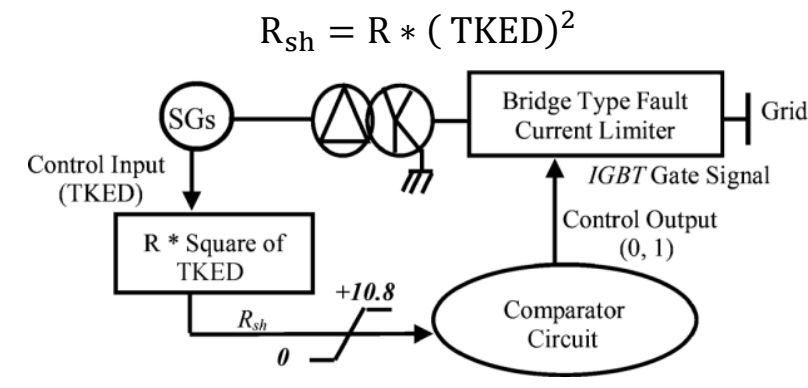

Static nonlinear controller connection scheme with bridge type FCL.

The block diagram of the static nonlinear controller. The optimal value of the controller parameter is 0.024 . This optimal value is determined by trial and error method. As we used a simple nonlinear controller, the value of the controller constant has paramount effect on the operation of the nonlinear controller controlled BFCL. We noticed if the value of is beyond some range, then the performance of BFCL changes rapidly. That range is given in the next paragraph. It is important to note that the same parameter is used throughout the simulations. Again, the comparator operation is designed in the same way as for the fuzzy logic controller. The IGBT switch will turn on only when the gate signal is 1 . On the other hand, it remains off when the gate signal is less than 1 .

For designing the nonlinear controller, the TKED square of the generators in the system is multiplied with a controller constant. The reason behind multiplying with $\mathrm{R}$ is, without any constant, the TKED variation will be very abrupt and out of control. Moreover, the square of TKED is chosen as it represents a very simple nonlinear controller. From our observation we came to a very important decision about choosing the value for $\mathrm{R}$. We observed that has a range of value beyond which the system becomes unstable and out of control. In concrete form, the range of is

$$
0.024 \leq \mathrm{R}<0.055 \text { (approximately) }
$$


If we decrease the value of from higher to lower, then the system performance becomes better. On the other hand, beyond the lower limit, the system becomes unstable due to the over compensation of the controller. The controller constant $\mathrm{R}$ is used to limit the high variation of TKED in the controller. The lower the value of $\mathrm{R}$ will be, the less abrupt the TKED variation will be, as $\mathrm{R}$ is multiplied with the TKED square in the controller. Therefore, in this work, we observed that beyond the lower limit of the range of $\mathrm{R}$, the variation of TKED becomes trivial and it has a steady response within the limit of the limiter in the next stage. Thus the nonlinear controller has a steady response and it degrades the BFCL operation if we choose a value of beyond the lower limit. Similarly, if we increase the value of from lower to higher, the performance of the BFCL degrades. If the value of $\mathrm{R}$ increases beyond the higher limit of the controller constant's range, then due to higher abruption of the TKED variation the BFCL's operation degrades and the whole system becomes unstable

\section{SIMULATION RESULT}

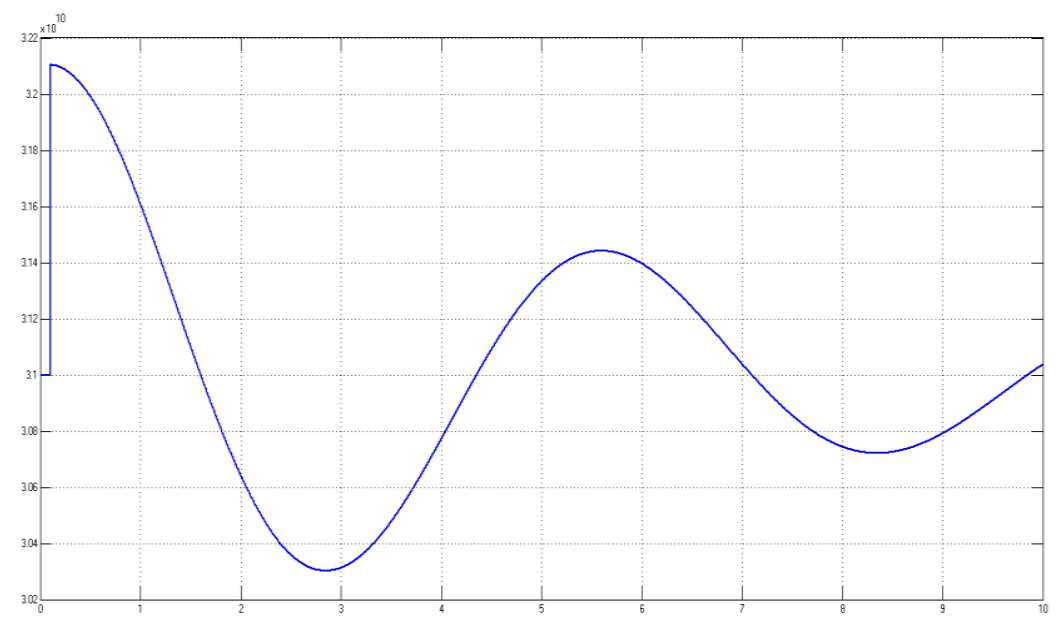

Figure 1 Output for Total Kinetic energy response:
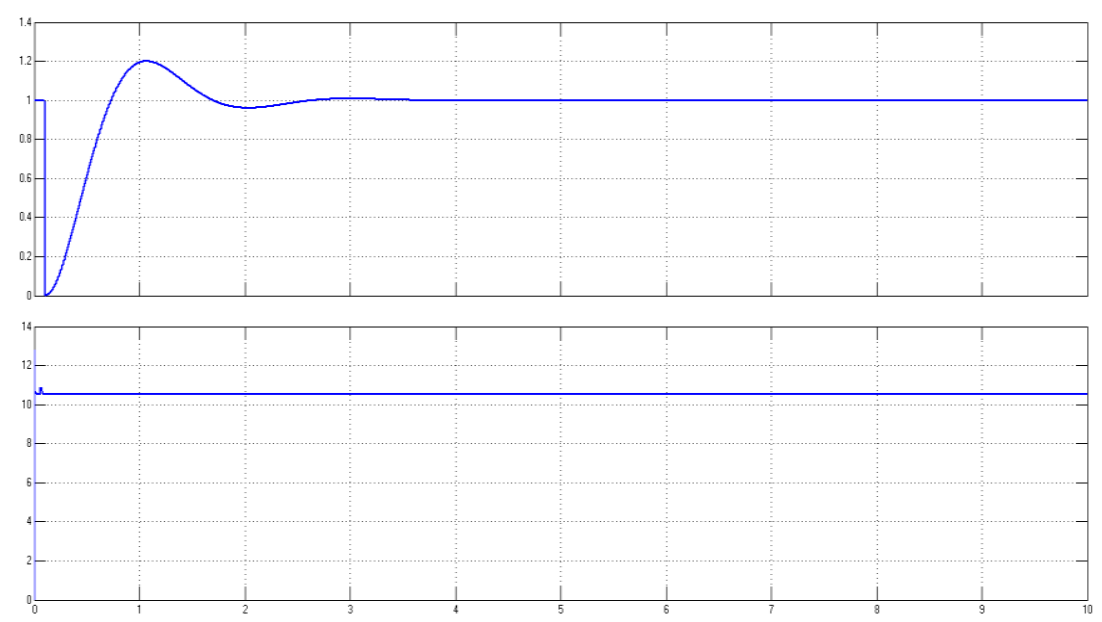

Figure 2 Magnitude and Phase voltage output 


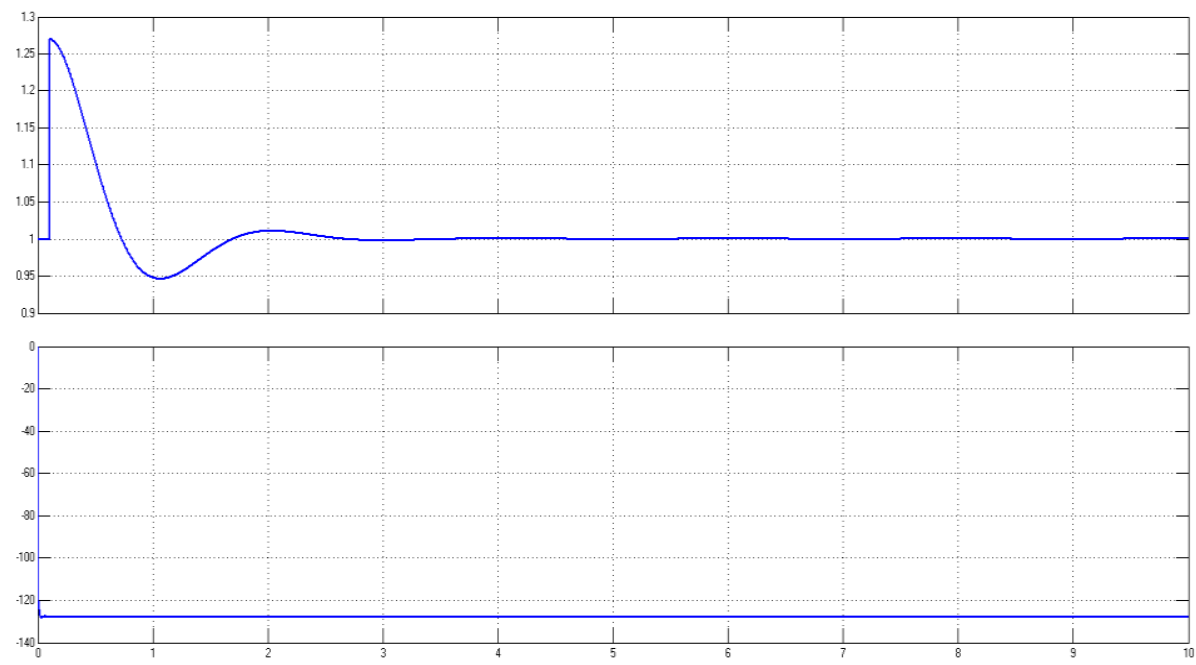

Figure 3 Magnitude and Phase current output

\section{CONCLUSION}

This paper proposes the application of static non-linear controlled bridge type FCL for improving the transient stability of multi-machine power systems. The performance of the static non-linear controlled bridge type FCL is compared with that of the Fuzzy Logic controlled bridge type FCL. From the simulation plots and index values, the following conclusions can be drawn.

a) The proposed static non-linear controlled bridge type FCL can improve the transient stability of the multi-machine power systems.

b) The transient stability performance of the static non-linear controlled bridge type FCL is better than that of the fuzzy logic controlled bridge type FCL.

Therefore, the proposed static non-linear controlled bridge type FCL can be considered as an effective means for transient stability enhancement in multi-machine power systems. In our future work we would like to address the communication delay problem and propose solutions to reduce the negative effect of delay. Moreover, we also would like to explore other types of fault current limiters for power system transient stability enhancement. Also, since the proposed controller will handle input and output signals, during signal transmission there might be possible cyber-attacks or hacking. In the future, possible cyber vulnerabilities of the static non-linear controller considering its cyber physical architecture and the solutions will be studied.

\section{REFERENCES}

[1] CH. Ram Jethmalani V. Karthikeyan and Narayanapa," Implementation of UPQC for Voltage Sag Mitigation", International Journal of Computer Communication and Information System (IJCCIS) - Vol2. No1. ISSN: 0976-1349 July - Dec 2010

[2] Devendra Mittal, om Prakash mahela, Rohitha Jain "detection and analysis of power quality disturbances under faulty conditions in electrical power system "(ISSN 09766545) March-April (2013)

[3] Thomas, R., Narayanappa, Thanushkodi. (2013). Reactive power compensation in electrical traction Using Active impedance concepts. 2013 International Conference on Circuits, Power and Computing Technologies (ICCPCT). Anandkumar G, B.J Shah "small signal stability improvement of multi machine power system using power 
system stabilizer "(ISSN 0976-6553) (IJEET) Volume 9, Issue 2, March- April 2018

[4] P. Kundur, Power System Stability and Control. New York, NY, USA: McGraw-Hill, 1994.

[5] M. A. H. Saudi and M. H. Ali, "Combined operation of SFCL and optimal reclosing of circuit breakers for power system transient stability enhancement," in Proc. IEEE SoutheasrCon. 2013, Jacksonville, FL, USA, 2013.

[6] M. Tsuda, Y. Mitanni, K. Tsuji, and K. Kaki Hana, "Application of resistor based superconducting fault current limiter to enhancement of power system transient stability," IEEE Trans. Appl. Super Cond., vol.11, pp. 2122-2125, Mar. 2001.

[7] M. Sjostrom, R. Cherkaoui, and B. Dutoit, "Enhancement of power system transient stability using superconducting fault current limiters," IEEE Trans. Appl. super Cond., vol. 9, pp. 1328-1330, Jun. 1999.

[8] H.-S. Choi, S.-H. Lim, D.-C. Chung, B.-S. Han, O.-B. Hyun, and T.-H. Sung, "Responses of resistive superconducting-fault-current-limiters to unbalanced faults," 